\title{
Exploring the Potential for Fungal Antagonism and Cell Wall Attack by Bacillus subtilis natto
}

\author{
Anna Schönbichler ${ }^{1+}$, Sara M. Díaz-Moreno ${ }^{1}$, Vaibhav Srivastava ${ }^{1}$ and \\ Lauren Sara McKee ${ }^{1,2 *}$ \\ ${ }^{1}$ Division of Glycoscience, Department of Chemistry, KTH Royal Institute of Technology, AlbaNova University Centre, \\ Stockholm, Sweden, ${ }^{2}$ Wallenberg Wood Science Center, Stockholm, Sweden
}

OPEN ACCESS

Edited by:

Ying Ma,

University of Coimbra, Portugal

Reviewed by:

M. Oves,

King Abdulaziz University,

Saudi Arabia

Jay Prakash Verma

Banaras Hindu University, India

*Correspondence:

Lauren Sara McKee

mckee@kth.se

${ }^{\dagger}$ Present address:

Anna Schönbichler,

Unit of Functional Cancer Genomics, University of Veterinary Medicine

Vienna, Vienna, Austria

Specialty section:

This article was submitted to

Microbiotechnology,

a section of the journal

Frontiers in Microbiology

Received: 16 January 2020

Accepted: 10 March 2020

Published: 31 March 2020

Citation:

Schönbichler A, Díaz-Moreno SM,

Srivastava V and McKee LS (2020)

Exploring the Potential for Fungal

Antagonism and Cell Wall Attack by

Bacillus subtilis natto.

Front. Microbiol. 11:521.

doi: 10.3389/fmicb.2020.00521
To develop more ecologically sustainable agricultural practices requires that we reduce our reliance on synthetic chemical pesticides for crop protection. This will likely involve optimized biocontrol approaches - the use of beneficial soil microbes to attack potential plant pathogens to protect plants from diseases. Many bacterial species, including strains of Bacillus subtilis, have been explored for their biocontrol properties, as they can control the growth of harmful fungi, often by disrupting the fungal cell wall. A strain that is not often considered for this particular application is Bacillus subtilis natto, primarily known for fermenting soybeans via cell wall degradation in the Japanese probiotic dish "natto." Because deconstruction of the fungal cell wall is considered an important biocontrol trait, we were motivated to explore the possible anti-fungal properties of the $B$. subtilis natto strain. We show that $B$. subtilis natto can use complex fungal material as a carbon source for growth, and can effectively deconstruct fungal cell walls. We found degradation of fungal cell wall proteins, and showed that growth on a mix of peptides was very strong. We also found that intact fungal cell walls can induce the secretion of chitinases and proteases. Surprisingly, we could show that chitin, the bulk component of the fungal cell wall, does not permit successful growth of the natto strain or induce the secretion of chitinolytic enzymes, although these were produced during exposure to proteins or to complex fungal material. We have further shown that protease secretion is likely a constitutively enabled mechanism for nutrient scavenging by $B$. subtilis natto, as well as a potent tool for the degradation of fungal cell walls. Overall, our data highlight $B$. subtilis natto as a promising candidate for biocontrol products, with relevant behaviors that can be optimized by altering growth conditions. Whereas it is common for bacterial biocontrol products to be supplied with chitin or chitosan as a priming polysaccharide, our data indicate that this is not a useful approach with this particular bacterium, which should instead be supplied with either glucose or attenuated fungal material.

Keywords: biocontrol, Bacillus subtilis natto, Chitinase, fungal cell wall, protease, secretome 


\section{INTRODUCTION}

One of the greatest threats to global food security is the massive loss of staple crops to fungal disease (Dean et al., 2012; Fisher et al., 2012). To try to avoid devastating harvest losses, farmers apply increasing amounts of pesticides ( $\mathrm{Ng}$ et al., 2019). As a result, synthetic pesticides are often found at high levels in soil and water, and accumulate in food webs with increasing toxicity (Damalas and Eleftherohorinos, 2011; Jorgensen et al., 2012; Silva et al., 2019). This poses risks to environmental and human health, and contributes to the increasing incidence of fungal resistance to chemical pesticides (Deising et al., 2008; Price et al., 2015; Hawkins et al., 2018). It is therefore imperative that we find alternative approaches to crop protection. One popular suggestion is to increase the efficacy of biocontrol, which is the use of living organisms to control plant disease vectors. This includes certain bacteria that are naturally able to limit the growth of phytopathogenic fungi. The design of an effective bacterial biocontrol product is challenging, since a thorough understanding of target, environment, mode of action, and delivery system is needed (O'Brien, 2017). Biocontrol bacteria are often packaged together with chitin, which has long been thought to prime their anti-fungal behaviors (Sid Ahmed et al., 2003; Kokalis-Burelle et al., 2006; Yandigeri et al., 2015).

A bacterial species with well-known biocontrol capability is Bacillus subtilis, found in diverse environments, but generally regarded as a soil dweller (Kunst et al., 1997; Earl et al., 2008). When present in the rhizosphere of plants, B. subtilis conveys beneficial effects on plant growth, in addition to displaying fungal antagonism, and can limit the growth of phytopathogenic species (Cazorla et al., 2007; Choudhary and Johri, 2009; Kumar et al., 2012; Xiao-ying et al., 2015).

The ability of $B$. subtilis and other soil bacteria to secrete chitin-degrading enzymes (Figure 1) is often used as a proxy indicator for fungal-antagonistic properties (Sundheim, 1992; Swain et al., 2008; Swain and Ray, 2009; Luo et al., 2015; Veliz et al., 2017). Fungal cell wall deconstruction is viewed as a key element of fungal antagonism and therefore of antifungal biocontrol in general (Swiontek Brzezinska et al., 2014; O'Brien, 2017; Veliz et al., 2017). The fungal cell wall consists of a common core of $\beta-1,3-, \beta-1,6-D$-glucans and chitin. Chitin is a high molecular weight crystalline polysaccharide made of $N$-acetylglucosamine (GlcNAc) residues connected by $\beta$-1,4glycosidic linkages, and it provides strength and toughness to stabilize and protect the cell (Gow et al., 2017). The outer layer of the cell wall typically comprises highly mannosylated glycoproteins (Gow et al., 2017).

The addition of chitin directly into soil can increase soil suppressiveness, likely by causing an increase in the production of bacterial chitinases or other antagonistic metabolites (Cretoiu et al., 2013; Debode et al., 2016). A key question remains to be answered: does the addition of chitin lead to an increase in chitinase activity because of an increase in cell numbers of chitinase-secreting bacteria, or because bacterial cells experience a specific upregulation in expression of chitinase-encoding genes?

Bacillus subtilis natto (Qiu et al., 2004; Nishito et al., 2010; Kamada et al., 2014) is a well-known Japanese strain, primarily used in the agricultural setting for food production (Horie et al., 2018; Wang et al., 2018). In the famous natto fermentation process, secreted bacterial proteolytic and glycolytic enzymes transform soybeans into a probiotic food (Kuo et al., 2006; $\mathrm{Hu}$ et al., 2010; Lee et al., 2019). Analysis of the published genome of B. subtilis natto strain BEST195 (Nishito et al., 2010; Kamada et al., 2014) reveals a number of possible chitin degrading enzymes, including a chitosanase and multiple hexosamininidases (Figure 1). This is in addition to the numerous well-known proteases the species produces (Weng et al., 2017). We were motivated to explore the extent to which B. subtilis natto is capable of deconstructing the chitinand protein-rich fungal cell wall, and whether the bacterium modulates the production of degradative enzymes upon sensing the main components of a fungal cell wall.

We have assayed B. subtilis natto for its ability to draw nutrition from complex fungal cell wall material and its three main components - chitin, $\beta$-glucan, and protein - using growth analyses, biochemical assay, and proteomic assay of the bacterial secretome. By exploring the factors that can promote classical biocontrol activities in B. subtilis natto, we believe that more effective optimized formulations of the bacterium can be developed that have stronger and longer lasting protective effects, thereby improving the cost-efficacy of the technology (Barratt et al., 2018). We found that this strain can indeed metabolize fungal cell walls, and secretes high levels of chitinase and protease activities during growth - but that neither chitin nor $\beta$-glucan supported strong growth or elevated enzyme secretion. We propose that pre-cultivating B. subtilis natto with fungal cell wall extract - but not isolated chitin polysaccharide - may prime the bacterium for stronger biocontrol behavior in the field.

\section{MATERIALS AND METHODS}

\section{Growth Analyses of B. subtilis natto Preparation of Growth Substrates}

Mushrooms of the species Agaricus bisporus were purchased from a grocery store, cut into small pieces, and lyophilized over a weekend. The dried pieces were then ground into a fine powder using a bead mill tissue homogenizer. Fungal cell wall (FCW) was extracted in the form of an alcohol insoluble residue (AIR), according to the method described by Smiderle et al. (2013). Approximately $3 \mathrm{~g}$ of fungal powder was incubated overnight in $30 \mathrm{~mL}$ of $70 \%$ ethanol on a shaking bench. Ethanol was removed by centrifugation for $10 \mathrm{~min}$ at $5000 \times g$. The supernatant fluid was discarded, and the remaining pellet was washed in $25 \mathrm{~mL}$ $70 \%$ ethanol three times. The remaining pellet was then washed

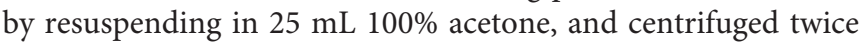
to remove all supernatant liquid. After the third wash, sample was transferred into an aluminium lined petri dish and left to dry overnight under air flow. The yield of AIR was approximately $30 \%$ of the initial A. bisporus fruiting body (FB) powder.

\section{Strain Maintenance and Growth Rate Analysis}

A lyophilized pellet of cultured B. subtilis natto (DSM1092) was purchased from DSMZ (Braunschweig, Germany) 

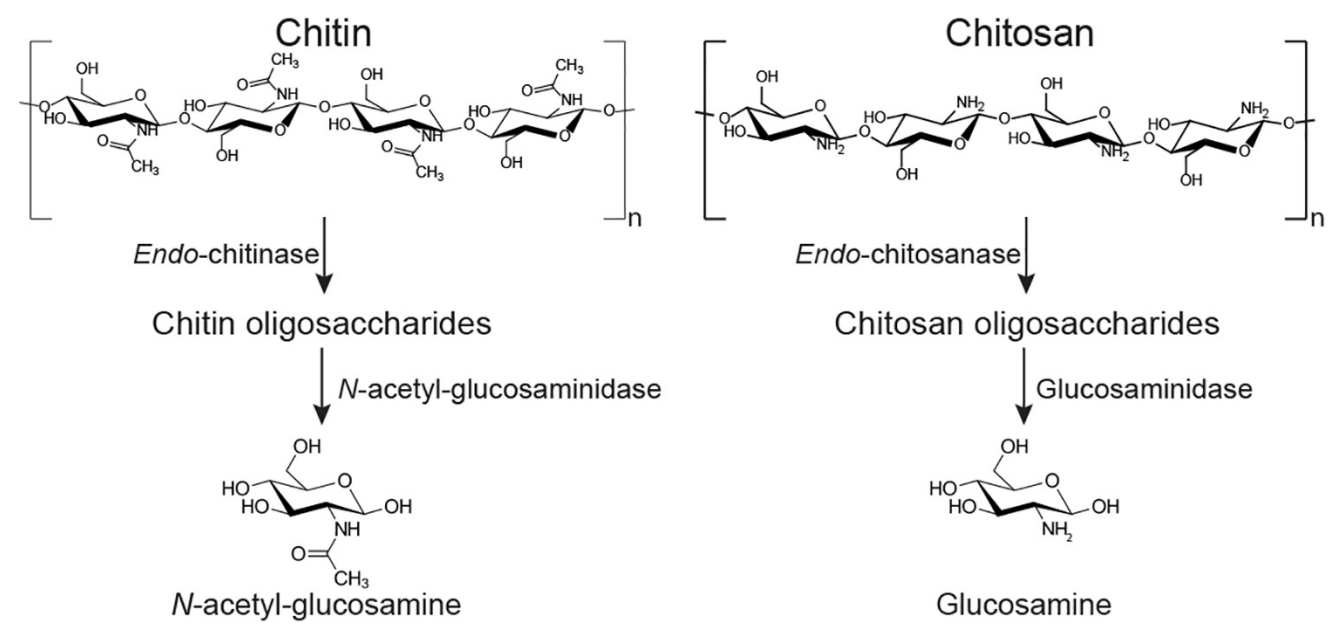

Glucosamine

FIGURE 1 | Simplified depiction of two potential chitin degradation pathways. Chitin can be deconstructed to oligosaccharides by an endo-chitinase (EC 3.2.1.14); the oligos are converted to monosaccharide GlcNAc by an exo-acting $N$-acetylglucosaminidase (EC 3.2.1.30). The (partly) deacteylated form chitosan can be hydrolyzed by an endo-chitosanase (EC 3.2.1.132) into oligosaccharides, prior to deconstruction by exo-enzymes such as glucosaminidase (EC 3.2.1.165). Most chitin deacetylating enzymes (EC 3.5.1.41) are more active on lower molecular weight chito-oligosaccharides than on very high molecular weight polysaccharides (Zhao et al., 2010).

and rehydrated in $700 \mu \mathrm{L} \mathrm{LB}$ medium prior to overnight propagation at $30^{\circ} \mathrm{C}$ in $10 \mathrm{~mL} \mathrm{LB}$ medium. For long-term storage at $-80^{\circ} \mathrm{C}, 500 \mu \mathrm{L}$ aliquots of liquid culture were added to $200 \mu \mathrm{L} 80 \%$ glycerol. To generate detailed growth curves of $B$. subtilis natto provided with different substrates (carbon sources putatively able to induce an anti-fungal effect), $100 \mu \mathrm{L}$ from $10 \mathrm{~mL}$ starting cultures grown overnight in LB medium, were inoculated into $10 \mathrm{~mL}$ Spizizen minimal medium (Anagnostopoulos and Spizizen, 1961). $1 \mathrm{~L}$ of Spizizen minimal medium contained $2 \mathrm{~g}\left(\mathrm{NH}_{4}\right)_{2} \mathrm{SO}_{4}, 14 \mathrm{~g} \mathrm{~K}_{2} \mathrm{HPO}_{4}$,

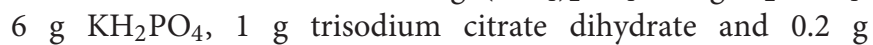
$\mathrm{MgSO}_{4} \cdot 7 \mathrm{H}_{2} \mathrm{O}$, as well as $0.01 \mathrm{~g}$ Yeast Extract and $0.85 \mathrm{mg}$ $\mathrm{MnSO}_{4}$ (Hauser and Karamata, 1994). Cultures (10 mL) were additionally supplemented with $50 \mathrm{mg}$ of either $A$. bisporus FB powder, A. bisporus FCW, $\beta$-chitin (Maharani Chitosan PTV, Ltd., Gujarat, India), the branched fungal $\beta$-glucan scleroglucan (Cargill, MN, United States), or peptone (SigmaAldrich, MO, United States). For each carbon source tested, three cultures with and three cultures without $0.5 \%$ glucose were prepared. Cultures were incubated at $30^{\circ} \mathrm{C}$ with rotary shaking at $200 \mathrm{rpm}$. $300 \mu \mathrm{L}$ samples were taken hourly and absorbance readings $\left(\mathrm{A}_{600}\right)$ were taken after solid material had settled. Control growth experiments provided Spizizen medium with/without glucose and no additional carbon source. Noninoculated bacterial free cultures (BFC) were also prepared to account for the absorbance deriving from dissolved or dispersed carbon source.

\section{Secretome Analysis}

\section{Collection and washing of secreted proteins}

After cultures of B. subtilis natto reached stationary phase, cultures were centrifuged $(5000 \times g, 30 \mathrm{~min})$ and cell-free supernatant (CFS) was carefully removed by pipetting into a fresh tube. Control secretome experiments used the CFS from
BFC experiments, prepared in the same way. After collecting the CFS, aliquots were washed twice in $\mathrm{H}_{2} \mathrm{O}$ using Amicon Ultra 0.5 Centrifugal Filter Units with $10 \mathrm{kDa}$ nominal molecular weight cut-off (Merck, Darmstadt, Germany). A Bradford Protein Assay was performed to measure the protein concentration. Briefly, Bradford Dye Reagent (Bio-Rad Laboratories, CA, United States) was diluted 1:4 in $\mathrm{H}_{2} \mathrm{O}$. In a 96-well plate, $10 \mu \mathrm{L}$ of CFS were mixed with $200 \mu \mathrm{L}$ of diluted Bradford Dye Reagent and incubated at room temperature for $5 \mathrm{~min}$. Absorbance was measured at $595 \mathrm{~nm}$ using a BMG Labtech CLARIOstar spectrophotometer (BMG labtech, CA, United States). Protein concentration was quantified by comparison to a standard curve produced using Bovine Serum Albumin (Bio-Rad Laboratories, CA, United States).

\section{Secretome SDS-PAGE}

To visualize the proteins present, CFS samples were analyzed via SDS-PAGE. For this, $5 \mathrm{~mL}$ of CFS was concentrated to $\sim 500 \mu \mathrm{L}$ using Amicon Ultra 0.5 Centrifugal Filter Units with $10 \mathrm{kDa}$ nominal molecular weight cut-off (Merck, Darmstadt, Germany). Approximately equal total amounts of protein were loaded onto an SDS-PAGE gel, dyed using InstantBlue Stain (Sigma-Aldrich, MO, United States).

\section{Sample preparation for mass spectrometric analysis}

To identify proteins visualized by SDS-PAGE, trypsin in-gel digestion was performed as described previously in Srivastava et al. (2013). Briefly, bands of interest were cut out of the gel and diced into $\sim 1 \mathrm{~mm}^{3}$ pieces. These were incubated in $200 \mu \mathrm{L}$ gel reagent $(50 \% 0.1 \mathrm{M}$ ammonium carbonate, $50 \%$ acetonitrile, $\mathrm{pH}$ 10) at $37^{\circ} \mathrm{C}$ for $60 \mathrm{~min}$. Gel pieces were dehydrated by mixing with $100 \%$ acetonitrile. Next, $100 \mu \mathrm{L}$ of a $10 \mathrm{mM}$ solution of DTT in $50 \mathrm{mM}$ ammonium bicarbonate was added to the gel pieces, and incubated for $30 \mathrm{~min}$ at $60^{\circ} \mathrm{C}$. After removing and discarding 
excess supernatant, $30 \mu \mathrm{L}$ of $1 \%$ iodoethanol solution in $50 \mathrm{mM}$ ammonium bicarbonate was added for a 15-minute incubation at $37^{\circ} \mathrm{C}$. Dehydration with $100 \%$ acetonitrile was repeated. To digest proteins in the gel, $30 \mu \mathrm{L}$ trypsin solution (comprising trypsin $(10 \mathrm{ng} / \mu \mathrm{L})$ and Protease Max $(0.01 \%)$ in $50 \mathrm{mM}$ ammonium bicarbonate) was added to dehydrated pieces, for incubation on ice for $15 \mathrm{~min}$. Excess trypsin solution was removed, and $50 \mu \mathrm{L}$ of $50 \mathrm{mM}$ ammonium bicarbonate solution was added for overnight incubation at $37^{\circ} \mathrm{C}$. Supernatant containing released peptides was transferred to a fresh tube. Additional peptides were extracted from the gel pieces using $50 \mu \mathrm{L}$ formic acid solution ( $5 \%$ formic acid, 50\% acetonitrile, $45 \% \mathrm{H}_{2} \mathrm{O}$ ), and incubated for $5 \mathrm{~min}$ at room temperature. Peptides were speed-vacced to dryness and stored at $-20^{\circ} \mathrm{C}$ until analysis by mass spectrometry.

\section{Mass spectrometric analysis}

Peptide analysis and identification was performed as described by Srivastava et al. (2013). A reversed-phase liquid chromatography electrospray ionization mass spectrometer (LC-ESI-MS/MS), using a nanoACQUITY ultra-performance liquid chromatography (UPLC) system coupled to a Q-TOF mass spectrometer (Xevo Q-TOF; Waters, Milford, MA, United States) was used. Briefly, peptides were loaded onto a C18 trap column (Symmetry $180 \mu \mathrm{m} \times 20 \mathrm{~mm}, 5 \mu \mathrm{m}$; Waters, Milford, MA, United States) followed by washing with $1 \%$ $(\mathrm{v} / \mathrm{v})$ acetonitrile and $0.1 \%(\mathrm{v} / \mathrm{v})$ formic acid at $10 \mu \mathrm{L} \mathrm{min} \mathrm{m}^{-1}$ for $5 \mathrm{~min}$. The samples eluted from the trap column were separated on a C18 analytical column $(75 \mu \mathrm{m} \times 100 \mathrm{~mm}$, $1.7 \mu \mathrm{m}$; Waters, Milford, MA, United States) at $250 \mathrm{nl} \mathrm{min}{ }^{-1}$ using $0.1 \%$ formic acid as solvent $\mathrm{A}$ and $0.1 \%$ formic acid in acetonitrile as solvent $\mathrm{B}$ in a stepwise gradient: $0.1 \%-10 \% \mathrm{~B}$ (0-5 min), $10-30 \%$ B (5-32 $\mathrm{min}), 30-40 \%$ B (32-35 $\mathrm{min})$, $40-85 \%$ B (36-38 $\mathrm{min}), 85 \%$ B (38-40 $\mathrm{min}), 85-0.1 \% \quad \mathrm{~B}$ (40-42 $\mathrm{min})$, and $0.1 \% \mathrm{~B}$ (42-60 $\mathrm{min})$. The eluting peptides were sprayed in the mass spectrometer (capillary and cone voltages set to $2.1 \mathrm{kV}$ and $35 \mathrm{~V}$, respectively), and MS/MS spectra were acquired using automated data-directed switching between the MS and MS/MS modes using the instrument software (MassLynx V4.0 SP4). The three most abundant signals of a survey scan (400-1600 m/z range, $1 \mathrm{~s}$ scan time) were selected by charge state, and collision energy was applied accordingly for sequential MS/MS fragmentation scanning (50-1800 m/z range, $1 \mathrm{~s}$ scan time). The MS raw data files were processed using Mascot Distiller (version 2.4.3.2, Matrix Science, London, United Kingdom) and the resulting files were submitted to a local Mascot (Matrix Science, version 2.3.1) server using the NCBI database with both $B$. subtilis (1084562 sequences) and general fungi (5915770 sequences) taxonomies. The following settings were used for the database search: trypsin-specific digestion with one missed cleavage allowed, ethanolylated cysteine as fixed and oxidized methionine as variable modifications, peptide tolerance of $100 \mathrm{ppm}$, and fragment tolerance of 0.6 Da. Peptides with Mascot ion scores exceeding the threshold for statistical significance $(p<0.05)$ were approved. Only proteins identified by two or more unique peptides were selected.

\section{Biochemical Assays \\ Chitosanase assay}

The blue colored substrate azurine cross-linked (AZCL)-chitosan (Megazyme, Co., Wicklow, Ireland; Cat. No. I-AZCHANF) was used according to the manufacturer's instructions to screen secretomes for endo-chitosanase activity (Huang et al., 2017). $1 \mathrm{~mL}$ of washed CFS was mixed with $1 \mathrm{~mL}$ AZCL-chitosan ( $2 \mathrm{~g} \mathrm{~L}^{-1}$ in $\mathrm{H}_{2} \mathrm{O}$ ) and incubated at $30^{\circ} \mathrm{C}$ with rotary shaking. The negative control contained $1 \mathrm{~mL}$ AZCL-chitosan and $1 \mathrm{~mL}$ washed non-inoculated culture medium. Absorbance at $590 \mathrm{~nm}$ was measured after $15-20 \mathrm{~h}$ of incubation.

\section{Protease assay}

To quantify protease activity in the supernatant of B. subtilis natto, a Pierce Protease Assay Kit (Thermo Scientific, Rockford, United States) was used according to the manufacturers' instructions (Rao et al., 1997; Tian et al., 2004). Briefly, $100 \mu \mathrm{L}$ of succinylated casein solution was added into microplate wells. $50 \mu \mathrm{L}$ of CFS was added on this, and the microplate was incubated for $20 \mathrm{~min}$ at $27^{\circ} \mathrm{C}$. After the incubation, $50 \mu \mathrm{L}$ of 2,4,6-trinitrobenzene sulfonic acid (TNBSA) working solution was added to the wells, and the plate was allowed to develop for $20 \mathrm{~min}$ in the dark at room temperature. Absorbance was then measured at $450 \mathrm{~nm}$ in a plate reader (CLARIOstar, BMG Labtech). Control experiments (CFS without succinylated casein) were subtracted from the measured absorption. Trypsin activity (Thermo Scientific) against the same substrate was used as a general protease standard.

\section{Assays using labeled monosaccharide substrates}

To measure GlcNAcase activity in the secretome of B. subtilis natto, pNP assays with 4-Nitrophenyl $\beta$-D-N-acetylglucosamine (Both Sigma-Aldrich, MO, United States) substrates were performed. For this, the substrate was dissolved in filtered $\mathrm{H}_{2} \mathrm{O}$ to achieve a $10 \mathrm{mM}$ stock concentration. To achieve complete dissolution, up to $3 \%$ DMSO was added. To prepare the assay, $20 \mu \mathrm{L}$ sodium phosphate buffer ( $\mathrm{pH}$ 6.5) was added to wells of a 96 well plate. To this was added $20 \mu \mathrm{L}$ of substrate (resulting in a final concentration of $1 \mathrm{mM}$ ) and $50 \mu \mathrm{L}$ of CFS, brought to a final volume $200 \mu \mathrm{L}$ with $\mathrm{H}_{2} \mathrm{O}$. For each type of CFS tested, a substrate blank, containing no pNP substrate, was also performed. The plate was incubated at $37^{\circ} \mathrm{C}$ for $6 \mathrm{~h}$ with absorbance measured at $410 \mathrm{~nm}$ in a plate reader (CLARIOstar, BMG Labtech) every hour. The amount of $\mathrm{pNP}$ produced was quantified by reference to a pNP standard curve.

To measure GlcNase activity in the secretome of B. subtilis natto, an assay with 4-Methylumbelliferyl (MU) $\beta$-DGlucosaminide (Carbosynth, Compton, United Kingdom) substrate was performed. For this, the substrate was dissolved in water to a stock concentration of $6 \mathrm{mM}$. The assay was prepared as described above, using a final substrate concentration of $0.6 \mathrm{mM}$. The plate was incubated at $37^{\circ} \mathrm{C}$ for $6 \mathrm{~h}$, and the release of fluorescent $4 \mathrm{MU}$ was measured in a BMG Labtech CLARIOstar fluorometer (BMG labtech, CA, United States) using a 340-380 nm bandpass excitation filter and a 455-465 nm 
bandpass emission filter. The amount of $4 \mathrm{MU}$ produced was quantified by reference to a $4 \mathrm{MU}$ standard curve.

\section{RESULTS AND DISCUSSION}

\section{Fungal Cell Walls - But Not Chitin - Are a Strong Growth Substrate for B. subtilis natto}

We first investigated the ability of $B$. subtilis natto to grow on fungal fruiting body (FB), extracted fungal cell wall (FCW), and the two major FCW carbohydrates - chitin and $\beta$-glucan - as sole carbon source. We also studied growth on a standard mix of soluble proteins (peptone), to serve as a mimic for the ill-defined protein component of FCW and other chitinous materials. The bacterium was incubated in minimal medium containing $5 \mathrm{~g}$ $\mathrm{L}^{-1}$ carbon source. Control experiments provided only minimal medium with no carbon source. All conditions were analyzed in triplicate. Cultures were sampled regularly for up to $26 \mathrm{~h}$, and optical density (OD) was measured as an indicator of culture turbidity. In addition, all of these conditions were studied both with and without the additional presence of $5 \mathrm{~g} \mathrm{~L}^{-1}$ glucose. This experimental set-up allowed us to investigate the potential for degradation of FCW and its components even when not being used as the primary carbon source supporting growth (i.e., the potential for co-metabolism of FCW components).

Growth in medium without glucose or any other experimental carbon source was very slow and reached a low final OD (Figure 2 and Table 1): the small amount of yeast extract in the un-supplemented minimal medium accounts for the low amount of growth that was achieved. Growth on glucose as
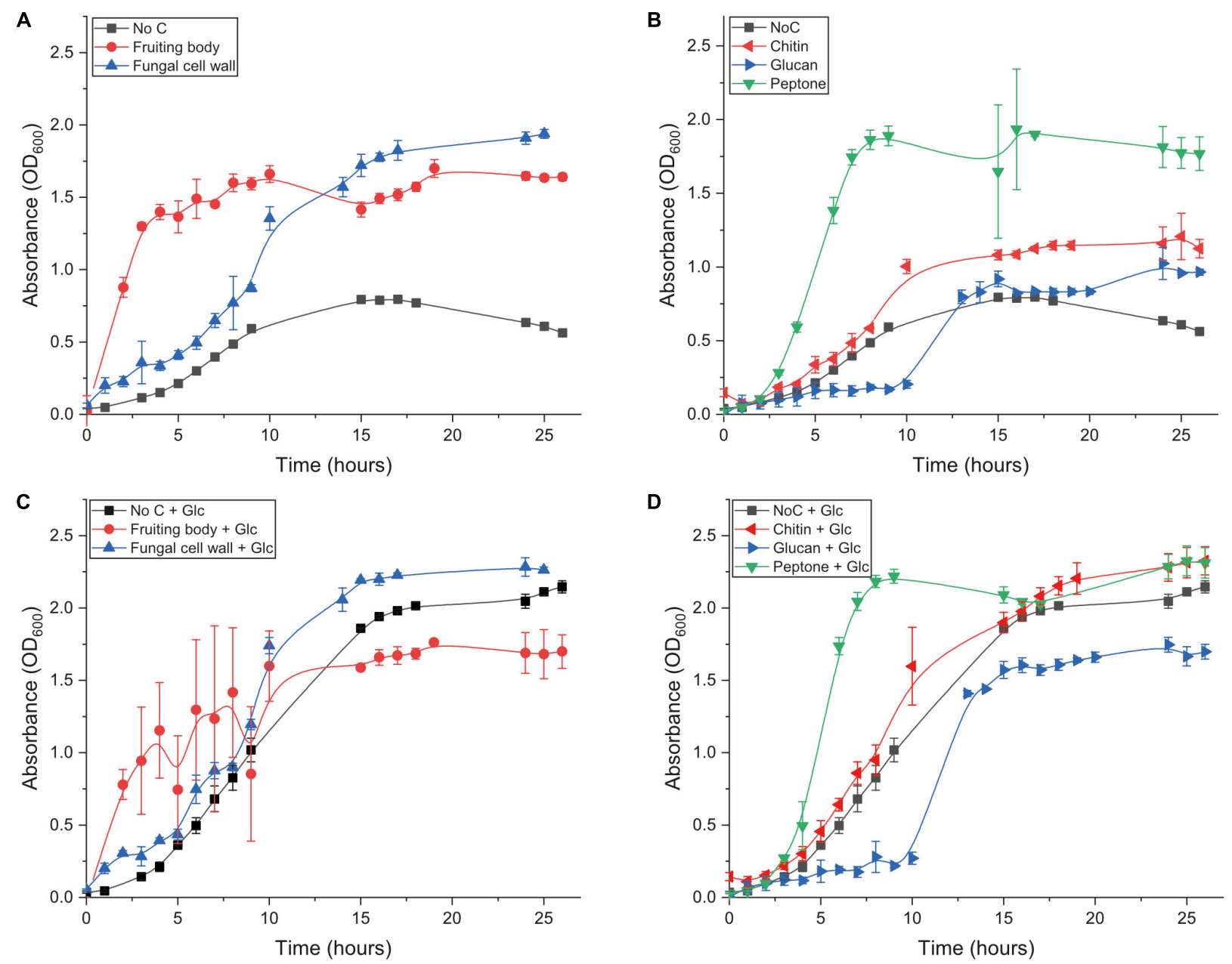

FIGURE 2 | Growth behavior of B. subtilis natto growing on different substrates. (A) Growth of B. subtilis natto on complex carbon sources: fungal fruiting body and fungal cell wall. (B) Growth of $B$. subtilis natto on isolated components of the fungal cell wall: $\beta$-chitin, $\beta$-glucan (scleroglucan), and peptone. (C) Growth of $B$. subtilis natto on fungal fruiting body and fungal cell wall, in medium additionally supplemented with glucose. (D) Growth of $B$. subtilis natto on $\beta$-chitin, $\beta$-glucan (scleroglucan), and peptone, in medium additionally supplemented with glucose. In all experiments, the bacterium was inoculated from LB starter cultures into 10 mL Spizizen minimal medium, additionally containing $50 \mathrm{mg}$ of the carbon source being tested. $\mathrm{OD}_{600}$ was measured regularly for up to $26 \mathrm{~h}$. Growth curves performed without experimental carbon source are included in both panels, labeled as No C. Raw absorbance data are provided for all growth curves in Supplementary Tables S1-S6. 
TABLE 1 | Summary of the growth behavior of $B$. subtilis natto.

\begin{tabular}{lcc}
\hline & $\begin{array}{c}\text { Relative doubling } \\
\text { rate }\end{array}$ & $\begin{array}{c}\text { Maximum OD } \\
\text { achieved }\end{array}$ \\
\hline No carbon source + Glucose & 1 & 2.15 \\
Fungal fruiting body + Glucose & 0.68 & 1.76 \\
Fungal cell wall + Glucose & 1.29 & 2.29 \\
$\beta$-chitin + Glucose & 0.83 & 2.33 \\
$\beta$-glucan + Glucose & 2.52 & 1.75 \\
Peptone + Glucose & 2.81 & 2.33 \\
No carbon source & 0.63 & 0.80 \\
Fungal fruiting body & 2.89 & 1.70 \\
Fungal cell wall & 0.91 & 1.94 \\
$\beta$-chitin & 0.80 & 1.21 \\
$\beta$-glucan & 1.32 & 1.02 \\
Peptone & 2.43 & 1.81 \\
\hline
\end{tabular}

The bacterium was cultivated in Spizizen minimal medium with or without glucose, containing carbon source at $5 \mathrm{~g} \mathrm{~L}^{-1}$. $O D_{600}$ was measured hourly over the course of $26 \mathrm{~h}$. Doubling rates were normalized by comparing to bacterium growing on glucose and no other carbon source.

sole carbon source was strong (Table 1 and Figure 2C). Only two experimental carbon sources permitted an increase in the baseline growth level of glucose cultures. Cultures supplemented with glucose and FCW reached a higher final OD than could be achieved on just glucose, while cultures supplemented with glucose and peptone showed a much more rapid doubling rate than during growth on only glucose (Table $\mathbf{1}$ and Figure 2C). This might indicate that only FCW and peptone are being used as carbon source instead of or as well as the glucose that is also present, while in all other glucose-supplemented cultures, it was only the glucose supporting bacterial growth, not the experimental carbon source. Growth experiments were repeated in the absence of glucose to test this theory.

Cultures lacking glucose showed that B. subtilis natto can indeed use fungal FB and especially FCW as a sole carbon source, showing a rapid doubling rate and reaching a high final OD (Figure 2A and Table 1). However, growth was very poor when the strain was provided with the main glycan components of the FCW, $\beta$-glucan and chitin (Figure 2B). Indeed, the fungal $\beta$-glucan scleroglucan supported the least growth of all carbon sources tested, and the concentration of secreted proteins was barely measurable; as a result, no further experiments were performed using that carbon source. Peptone as sole carbon source supported rapid growth (Figure 2B), perhaps indicating that proteins are a main metabolic focus for B. subtilis natto, explaining why the major glycan components of FCW fail to support strong growth (Table 1). Indeed, the ability of this strain to degrade proteins is quite well known and is exploited in the natto food production process, but we here show that this activity permits the strain to use peptides a sole carbon source during growth.

\section{Fungal Cell Walls - but Not Chitin - Induce the Secretion of Chitin-Degrading Enzymes}

Although growth on chitin was poor, a survey of the B. subtilis natto BEST195 strain reference genome had given several indications that chitin degradation by the strain is possible, as we found that it encodes a chitosanase, multiple de-acetylases, and several hexosaminidases/glucosaminidases (Qiu et al., 2003; Nishito et al., 2010; Kamada et al., 2014). In addition, chitin degradation is a focus of much biocontrol literature, and is often taken as a proxy for fungal antagonism (Veliz et al., 2017). During cultivation of $B$. subtilis natto on chitin, we observed a visible increase in dispersibility of the substrate, in terms of smaller particle size and a reduced tendency to settle at the bottom of the flask. This would imply that chitin is in fact being deconstructed, but the poor growth indicates that the bacterium is not readily able to take up the released chito-oligosaccharides, and/or is unable to metabolize those released sugars for energy. Analogy could be drawn with soil bacteria that are effective at deconstructing some types of $\beta$-glucan, but which show poor growth on these substrates due to an inability to take up the products of glucan deconstruction (McKee et al., 2019).

Due to the high background content of sugar in protein secretomes, even after repeated washing with water, we were unable to satisfactorily assay for chitin degradation. However, using a simple colorimetric assay, we were able to investigate the level of chitosanase activity in culture supernatants (secretomes) of B. subtilis natto (Figure 3) - chitosan is a de-acetylated form of chitin that can serve as an effective substrate for endo-acting chitosanase enzymes (Figure 1). No activity was detected from cultures grown on minimal medium lacking glucose or any carbon source. Perhaps surprisingly, the addition of chitin into this glucose-free growth medium did not lead to any chitosanase activity, suggesting that this carbohydrate does not induce a degradative pathway. The same was true

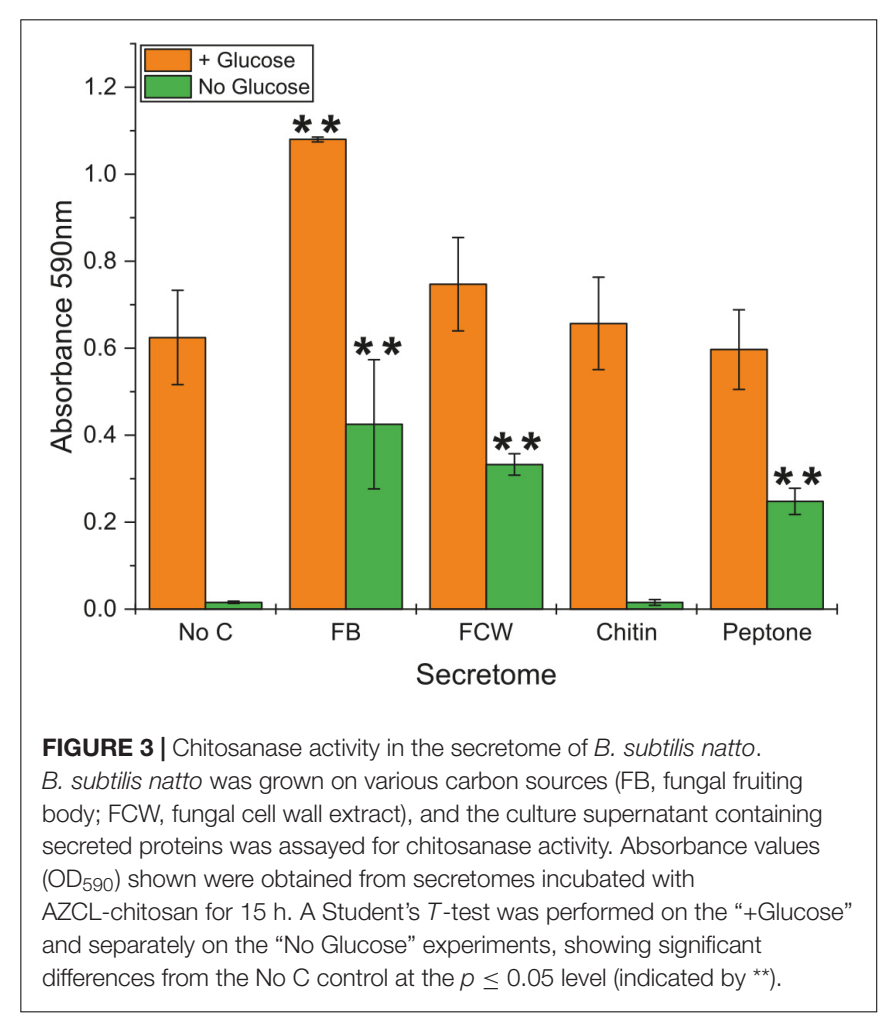


for glucose-free cultures grown with $\beta$-glucan. However, the inclusion of glucose in the medium did lead to detectable levels of secreted chitosanase activity, perhaps simply be causing an elevated protein concentration in the culture medium. Among the glucose-containing cultures, only fungal $\mathrm{FB}$ led to an increase in chitosanase activity (Figure 3). There was no such increase in cultures grown on FCW, chitin, or peptone. It is more interesting and useful to compare activity profiles of the cultures grown without glucose, where cells are forced to use the experimental carbon source for nutrition. Here we see that chitosanase activity is found in glucose-free cultures containing FB, FCW, or peptone. There is no activity in cultures grown on chitin, or grown without an experimental carbon source. This strongly indicates that complex fungal material and proteins - but not chitin itself - can induce the secretion of chitosanase activity. This assay measures absorbance values after enzyme incubation, but is not a directly quantitative measure of the release of a specific reaction product. As such, it was not feasible to accurately normalize these absorbance data by secretome protein concentration, so it is still possible that the increased chitosanase activity in fungal FB, FCW, and peptone cultures can simply be explained by a higher overall protein content in those secretomes, rather than the specific upregulation of chitosanase gene expression.

As discussed in the introduction, chitin can be degraded via two complementary pathways (Figure 1). To explore other potential routes to chitin deconstruction, we used two model substrates to screen for activity in the B. subtilis natto secretome: 4-nitrophenyl- $\beta$-D- $N$-acetylglucosamine (4NP-GlcNAc) and 4methylumbelliferyl- $\beta$-D-glucosamine ( $4 \mathrm{MU}-\mathrm{GlcN})$. These assays respectively, screen for the ability to deconstruct oligosaccharides of chitin (GlcNAc oligos) and chitosan (GlcN oligos), and verified that $B$. subtilis natto can indeed deconstruct both $\mathrm{GlcN}$ and GlcNAc oligosaccharides. Washed culture secretome was incubated with one of the two substrates for $4 \mathrm{~h}$, and activity was monitored by absorbance or fluorescence measurements every hour, producing a time-curve of activity (Figure 4). Using standard curves of $4 \mathrm{NP}$ and $4 \mathrm{MU}$, we could convert these measurements to concentrations of reaction

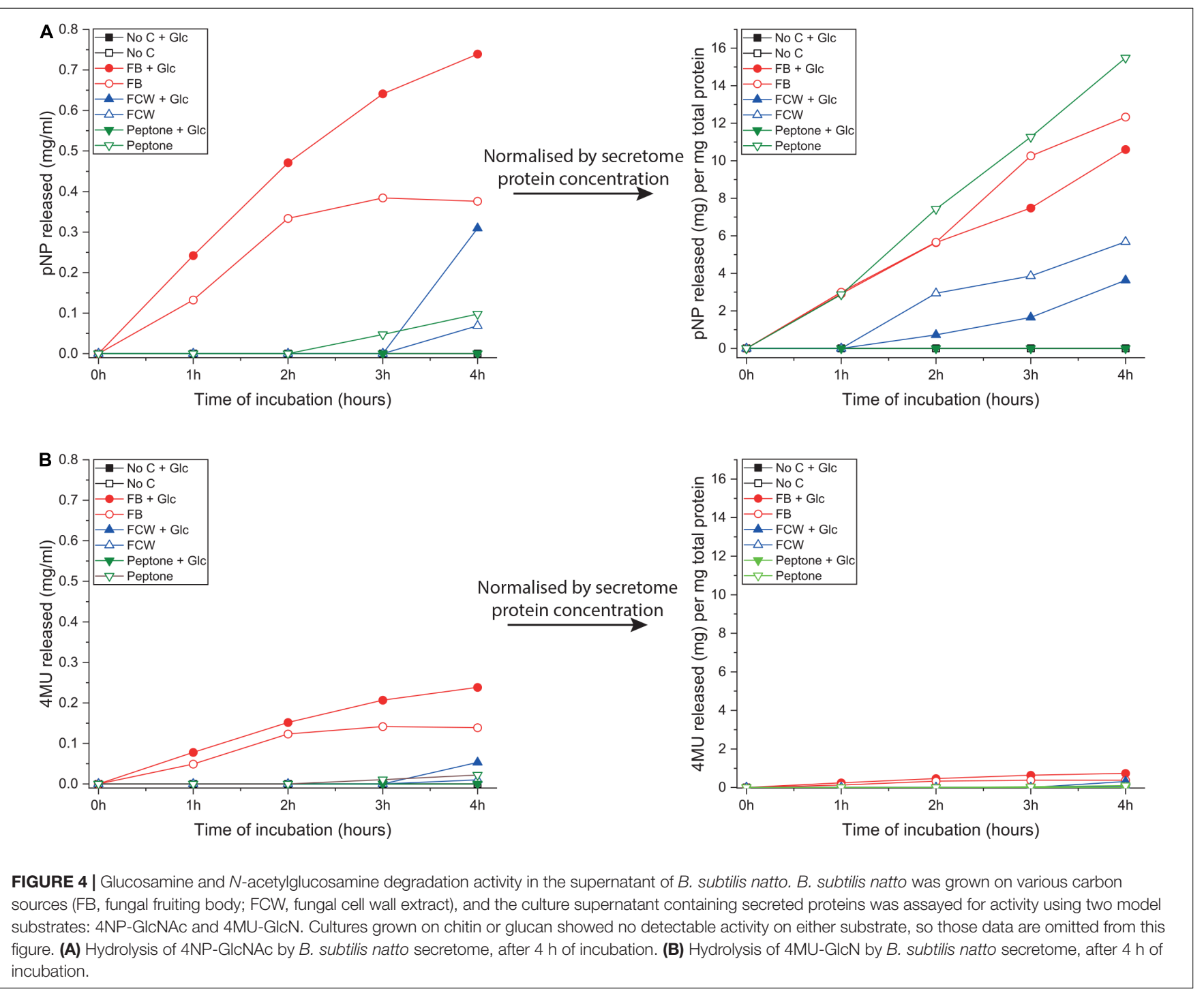


product released, and this could be normalized by secretome protein concentration.

Hydrolysis of 4NP-GlcNAc and 4MU-GlcN was only detected in cultures grown on peptone or one of the fungal substrates $\mathrm{FB}$ and FCW, indicating that enzyme production is being specifically activated by these substrates (Figure 4). As shown in Figure 4A, the highest levels of activity against $4 \mathrm{NP}-\mathrm{GlcNAc}$ were found in FB secretomes, regardless of the presence or absence of glucose in culture medium. However, after normalizing for total secretome protein concentration, the highest levels of $4 \mathrm{NP}-\mathrm{GlcNAc}$ activity per mg of secreted protein were found in peptone-induced secretomes. This suggests that, although there is more of the GlcNAc-ase enzyme(s) in the FB cultures, which had a higher total protein content than most other secretomes, there was a higher proportion of GlcNAc-ase enzyme(s) in the peptone-induced secretomes. This implies that there is a specific upregulation of gene(s) encoding GlcNAcase enzyme(s) during growth on peptone. To verify these indications, we attempted to quantify gene expression using qPCR. Despite repeated attempts, we were ultimately not able to find any reference genes that were stably expressed in all conditions tested.

Figure 4B shows that hydrolysis of $4 \mathrm{MU}-\mathrm{GlcN}$ was generally to a far lower level than for the GlcNAc substrate, but again the highest levels of activity were in the FB secretomes. Normalizing these activity data by total secretome protein concentration shows no obvious differences between the different carbon sources, suggesting that there is no activation of specific regulatory mechanisms, such as enhanced gene expression, that would lead to a higher level of GlcN-ase enzyme secretion.

\section{Proteases Are Secreted in All Conditions, and Enable Degradation of Fungal Cell Wall Proteins}

Inspired by the strong growth of B. subtilis natto on peptone and previous research indicating that protein digestion is integral to the natto food production process - we assayed our bacterial secretomes for protein degradation. An assay kit was used that compares proteolytic activity to that of purified trypsin enzyme, and showed that protease activity occurred in all glucose-supplemented cultures (Figure 5A). As with the earlier chitosanase activity test, only the FB-supplemented secretomes showed an increased level of protease activity. Comparing results from the no-glucose secretomes shows that the highest levels of protease activity are produced during growth on peptone and FCW, with somewhat lower levels of activity produced during growth on FB and even chitin. The secretion of proteases when proteins are present to be metabolized is logical, but the presence of these activities even during growth on glucose or chitin as sole carbon source suggests that more complex mechanisms are at play. It may be that several proteases are expressed in response to different carbon sources, in order to scavenge for proteins to metabolize. This would fortuitously permit the degradation of FCW when present, which is highly relevant to biocontrol and may largely explain the strong bacterial growth on fungal FB and FCW. According to the MEROPS Peptidase database ${ }^{1}$ (Rawlings et al., 2017), the published genome of B. subtilis natto strain BEST195 (Nishito et al., 2010; Kamada et al., 2014) encodes

${ }^{1}$ https://www.ebi.ac.uk/merops/
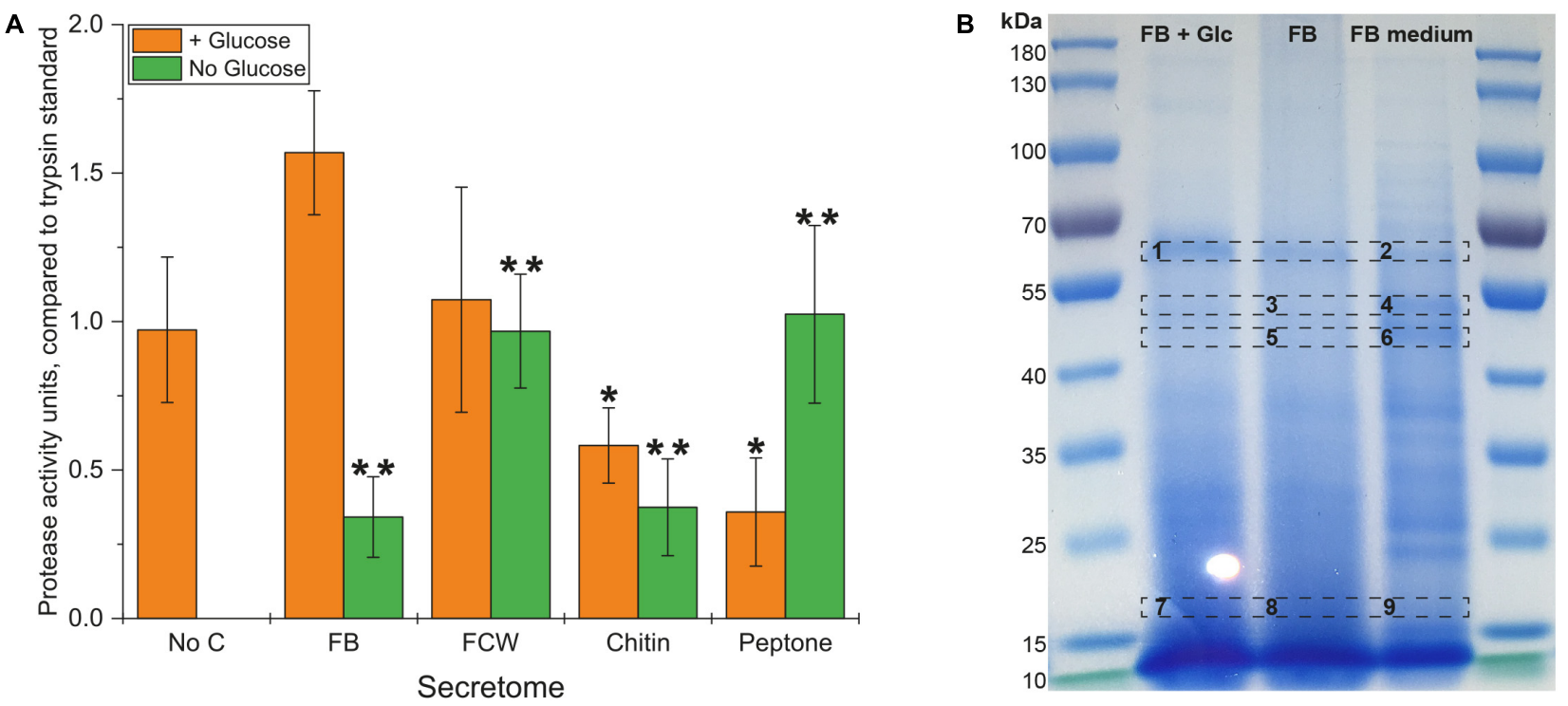

FIGURE 5 | Protease activity in the secretome of B. subtilis natto. (A) B. subtilis natto was grown on various carbon sources (FB, fungal fruiting body; FCW, fungal cell wall extract), and the culture supernatant containing secreted proteins was assayed for protease activity, comparing to the activity of a trypsin standard. A Student's T-test was performed on the "+ Glucose" and separately on the "No Glucose" experiments, showing significant differences from the No C control at the $p \leq 0.05$ level (indicated by ${ }^{* *}$ ) and the $p \leq 0.1$ level (indicated by *). (B) FB secretomes were concentrated and analyzed by SDS-PAGE. Proteins in the B. subtilis natto FB secretome (gel lanes FB + Glc and FB) were compared with the profile of proteins found in FB medium not inoculated with bacterium, which contained only proteins deriving from the fungal material itself. 
TABLE 2 | Proteins secreted by $B$. subtilis natto during growth on fungal fruiting body.

\begin{tabular}{|c|c|}
\hline B. subtilis natto culture secretome & Non-inoculated medium \\
\hline Band 1: 55-70 kDa & Band 2: 55-70 kDa \\
\hline $\begin{array}{l}\text { Peptide-binding protein } \\
\text { Dihydrolipoyl dehydrogenase } \\
\text { Peptidase G2 } \\
\text { Cytosol aminopeptidase }\end{array}$ & No bacterial proteins detected \\
\hline Band 3: 50-55 kDa & Band 4: 50-55 kDa \\
\hline $\begin{array}{l}2 \text { fungal proteins detected } \\
\text { Peptidase M42 } \\
\text { Cell wall-associated protease } \\
\text { precursor/Peptidase S8 } \\
\text { Gamma-glutamyltransferase } \\
\text { Bacillopeptidase F } \\
\text { Dihydrolipoyl dehydrogenase }\end{array}$ & $\begin{array}{l}21 \text { fungal proteins detected } \\
\text { No bacterial proteins detected }\end{array}$ \\
\hline $\begin{array}{l}\text { Band 5: } \mathbf{4 5} \text { - } \mathbf{5 5} \mathbf{~ k D a} \\
4 \text { fungal proteins detected } \\
\text { Peptidase M28 } \\
\text { Cell wall-associated protease precursor } \\
\text { Aminopeptidase } \\
\text { Extracellular protease vpr, partial } \\
\text { Dihydrolipoyl dehydrogenase } \\
\text { Gamma-glutamyltransferase } \\
\text { Major capsid protein } \\
\text { Hypothetical protein }\end{array}$ & $\begin{array}{l}\text { Band 6: } \sim \mathbf{4 5} \mathbf{- 5 5} \mathbf{~ k D a} \\
16 \text { fungal proteins detected } \\
\text { No bacterial proteins detected }\end{array}$ \\
\hline Bands 7 and $8: \sim 16-20 \mathrm{kDa}$ & Band 9: $\sim 16-20 \mathrm{kDa}$ \\
\hline $\begin{array}{l}\text { DNA starvation/stationary phase protection } \\
\text { protein } \\
\text { Superoxide dismutase } \\
\text { Cell wall-associated protease } \\
\text { precursor/Peptidase S8 } \\
\text { Serine hydroxymethyltransferase } \\
\text { Gamma-glutamyltranspeptidase, Glutathione } \\
\text { Hydrolase } \\
\text { DNA starvation/stationary phase protection } \\
\text { protein } \\
\text { Serine hydroxymethyltransferase } \\
\text { Aconitate hydratase 1 } \\
\text { Glucose-6-phosphate isomerase } \\
\text { Triscatecholate Siderophore Binding Protein } \\
\text { Acireductone dioxygenase } \\
\text { Phage-like element PBSX protein XkdM } \\
\text { Oligoendopeptidase F } \\
\text { Pectate Lyase }\end{array}$ & No bacterial proteins detected \\
\hline
\end{tabular}

See Supplementary Tables S7, S8 for a detailed description of all proteins identified in all proteomic experiments.

615 known or putative peptidases. Our own analysis of the predicted proteome of $B$. subtilis natto reveals nine enzymes predicted to be peptidases or proteases that are also predicted to be secreted into the extracellular space. Expression of one or more of these enzymes may be triggered during growth on glucose or chitin, but the precise mechanisms involved are still unknown.

Analysis of culture supernatants by SDS-PAGE (Figure 5B) showed that Spizizen medium supplemented with FB and not inoculated with any bacterium already contained a large number of proteins, deriving from the fungal material itself. Using proteomic mass spectrometry (MS), we could directly compare the profile of proteins in FB-supplemented medium with and without bacterial inoculation (Figure 5B). Several protein bands in the non-inoculated FB medium were reduced or absent following bacterial cultivation, while other bands became (more) visible after cultivation. Sections of the gel with the most visually apparent differences (indicated on Figure 5B) were excised from the gel, subjected to trypsin hydrolysis, and analyzed by MS. Table 2 summarizes the proteins found following bacterial cultivation on FB. A full list of proteins identified in our MS experiments is provided in Supplementary Tables S7, S8. Our analyses verified that a large number of proteins from the fungal material were degraded following incubation with growing cells of B. subtilis natto, as far fewer fungal proteins could be detected in equivalent samples after bacterial inoculation (Table 2 and Supplementary Tables S7, S8). Importantly, many of the $B$. subtilis natto proteins identified from our analyses as having been produced during growth on FB are predicted to be proteases. This supports our biochemical and growth data indicating that protease secretion is occurring in these growth conditions, and that these secreted proteases contribute to FCW deconstruction by hydrolyzing the protein component of FCW. This protein hydrolysis was likely a major contributor to the strong bacterial growth observed in FB and FCW cultures, as well as contributing to the visible increase in dispersibility of FCW particles during cultivation, as the strong network of the FCW was disrupted by protein degradation.

Due to the literature indicating that chitin can promote suppression of fungal pathogens by soil bacteria (Cretoiu et al., 2013; Debode et al., 2016), many biocontrol products are packaged with chitin as a priming agent. In the case of $B$. subtilis natto, however, our data indicate that such an approach would not encourage strong growth or an increase in FCW degradation. If $B$. subtilis natto is to be exploited as a biocontrol product, an alternative approach could be to use killed (attenuated) fungus as a priming agent in biocontrol products using B. subtilis natto to promote the secretion of chitin-, protein-, and FCWdegrading enzymes.

\section{CONCLUSION AND OUTLOOK}

We have demonstrated that the industrial strain B. subtilis natto is able to use complex fungal fruiting body and fungal cell wall as a carbon source, and that during growth on this material the species secretes chitin- and protein-degrading enzyme activities. We found conclusively that chitin - the bulk polysaccharide component of fungal cell walls, and a compound often used to stimulate biocontrol activities in soil bacteria - does not support growth of $B$. subtilis natto, nor does it induce the secretion of chitin-degrading activities. Through biochemistry and protein mass spectrometry, we have shown that a strong level of protease activity is produced in most conditions, confirming that this is the primary means by which B. subtilis natto draws nutrition from fungal cell walls. Further study is needed to verify that protein degradation in the cell wall can inhibit fungal growth. 


\section{DATA AVAILABILITY STATEMENT}

All datasets generated for this study are included in the article/Supplementary Material.

\section{AUTHOR CONTRIBUTIONS}

AS and LM designed the study. AS performed the experimental work, with contributions from SD-M and VS. LM supervised the project. AS and LM wrote the manuscript, with input from SD-M and VS.

\section{FUNDING}

This work was supported by funds awarded to LM by the Swedish Research Council Vetenskapsrådet (project 2017-04906), and by

\section{REFERENCES}

Anagnostopoulos, C., and Spizizen, J. (1961). Requirements for transformation in Bacillus subtilis. J. Bacteriol. 81, 741-746.

Barratt, B. I. P., Moran, V. C., Bigler, F., and van Lenteren, J. C. (2018). The status of biological control and recommendations for improving uptake for the future. BioControl 63, 155-167. doi: 10.1007/s10526-017-9831-y

Cazorla, F. M., Romero, D., Perez-Garcia, A., Lugtenberg, B. J., Vicente, A., and Bloemberg, G. (2007). Isolation and characterization of antagonistic Bacillus subtilis strains from the avocado rhizoplane displaying biocontrol activity. J. Appl. Microbiol. 103, 1950-1959. doi: 10.1111/j.1365-2672.2007.03 433.x

Choudhary, D. K., and Johri, B. N. (2009). Interactions of Bacillus spp. and plants With special reference to induced systemic resistance (ISR). Microbiol. Res. 164, 493-513. doi: 10.1016/j.micres.2008.08.007

Cretoiu, M. S., Korthals, G. W., Visser, J. H. M., and van Elsas, J. D. (2013). Chitin amendment increases soil suppressiveness toward plant pathogens and modulates the Actinobacterial and Oxalobacteraceal communities in an experimental agricultural field. Appl. Environ. Microbiol. 79:5291. doi: 10.1128/ AEM.01361-13

Damalas, C. A., and Eleftherohorinos, I. G. (2011). Pesticide exposure, safety issues, and risk assessment indicators. Int. J. Environ., Res. Public Health 8, 1402-1419. doi: 10.3390/ijerph8051402

Dean, R., Van Kan, J. A., Pretorius, Z. A., Hammond-Kosack, K. E., Di Pietro, A., Spanu, P. D., et al. (2012). The Top 10 fungal pathogens in molecular plant pathology. Mol. Plant Pathol. 13, 414-430. doi: 10.1111/j.1364-3703.2011. 00783.x

Debode, J., De Tender, C., Soltaninejad, S., Van Malderghem, C., Haegeman, A., Van der Linden, I., et al. (2016). Chitin mixed in potting soil alters lettuce growth, the survival of zoonotic bacteria on the leaves and associated rhizosphere microbiology. Front. Microbiol. 7:565. doi: 10.3389/fmicb.2016. 00565

Deising, H. B., Reimann, S., and Pascholati, S. F. (2008). Mechanisms and significance of fungicide resistance. Brazi. J. Microbiol. 39, 286-295. doi: 10. 1590/S1517-838220080002000017

Earl, A. M., Losick, R., and Kolter, R. (2008). Ecology and genomics of Bacillus subtilis. Trends Microbiol. 16, 269-275. doi: 10.1016/j.tim.2008.0 3.004

Fisher, M. C., Henk, D. A., Briggs, C. J., Brownstein, J. S., Madoff, L. C., McCraw, S. L., et al. (2012). Emerging fungal threats to animal, plant and ecosystem health. Nature 484, 186-194. doi: 10.1038/nature10947

Gow, N. A. R., Latge, J. P., and Munro, C. A. (2017). The fungal cell wall: structure, biosynthesis, and function. Microb. Spectrum 5, 1-25. doi: 10.1128/ microbiolspec.FUNK-0035-2016 the Knut and Alice Wallenberg Foundation via the Wallenberg Wood Science Centre. We are also grateful to KTH Royal Institute of Technology, CBH School for financial and practical support during this project.

\section{ACKNOWLEDGMENTS}

We are grateful to Sanjiv Kumar of KTH Division of Glycoscience for assistance with automated screening of the Bacillus subtilis natto genome and predicted proteome.

\section{SUPPLEMENTARY MATERIAL}

The Supplementary Material for this article can be found online at: https://www.frontiersin.org/articles/10.3389/fmicb. 2020.00521/full\#supplementary-material

Hauser, P. M., and Karamata, D. (1994). A rapid and simple method for Bacillus subtilis transformation on solid media. Microbiology 140(Pt 7), 1613-1617. doi: 10.1099/13500872-140-7-1613

Hawkins, N. J., Bass, C., Dixon, A., and Neve, P. (2018). The evolutionary origins of pesticide resistance. Biol. Rev. Camb. Philos. Soc. 94, 135-155. doi: 10.1111/ brv. 12440

Horie, M., Koike, T., Sugino, S., Umeno, A., and Yoshida, Y. (2018). Evaluation of probiotic and prebiotic-like effects of Bacillus subtilis $\mathrm{BN}$ on growth of Lactobacilli. J. Gen. Appl. Microbiol. 64, 26-33. doi: 10.2323/jgam.2017.03.002

Hu, Y., Ge, C., Yuan, W., Zhu, R., Zhang, W., Du, L., et al. (2010). Characterization of fermented black soybean natto inoculated with Bacillus natto during fermentation. J. Sci.Food Agric. 90, 1194-1202. doi: 10.1002/jsfa.3947

Huang, Y., Yi, Z., Jin, Y., Huang, M., He, K., et al. (2017). Metatranscriptomics reveals the functions and enzyme profiles of the microbial community in Chinese nong-flavor liquor starter. Front. Microbiol. 8:1747. doi: 10.3389/fmicb. 2017.01747

Jorgensen, L. F., Kjaer, J., Olsen, P., and Rosenbom, A. E. (2012). Leaching of azoxystrobin and its degradation product R234886 from Danish agricultural field sites. Chemosphere 88, 554-562. doi: 10.1016/j.chemosphere.2012.03.027

Kamada, M., Hase, S., Sato, K., Toyoda, A., Fujiyama, A., and Sakakibara, Y. (2014). Whole genome complete resequencing of Bacillus subtilis natto by combining long reads with high-quality short reads. PLoS One 9:e109999. doi: 10.1371/ journal.pone.0109999

Kokalis-Burelle, N., Kloepper, J. W., and Reddy, M. S. (2006). Plant growthpromoting rhizobacteria as transplant amendments and their effects on indigenous rhizosphere microorganisms. Appl.Soil Ecol. 31, 91-100. doi: 10. 1016/j.apsoil.2005.03.007

Kumar, P., Dubey, R. C., and Maheshwari, D. K. (2012). Bacillus strains isolated from rhizosphere showed plant growth promoting and antagonistic activity against phytopathogens. Microbiol. Res. 167, 493-499. doi: 10.1016/j.micres. 2012.05.002

Kunst, F., Ogasawara, N., Moszer, I., Albertini, A. M., Alloni, G., Azevedo, V., et al. (1997). The complete genome sequence of the gram-positive bacterium Bacillus subtilis. Nature 390, 249-256. doi: 10.1038/36786

Kuo, L. C., Cheng, W. Y., Wu, R. Y., Huang, C. J., and Lee, K. T. (2006). Hydrolysis of black soybean isoflavone glycosides by Bacillus subtilis natto. Appl. Microbiol. Biotechnol. 73, 314-320. doi: 10.1007/s00253-006-0474-7

Lee, J. H., Hwang, C. E., Son, K. S., and Cho, K. M. (2019). Comparisons of nutritional constituents in soybeans during solid state fermentation times and screening for their glucosidase enzymes and antioxidant properties. Food Chemi. 272, 362-371. doi: 10.1016/j.foodchem.2018.08.052

Luo, C., Zhou, H., Zou, J., Wang, X., Zhang, R., Xiang, Y., et al. (2015). Bacillomycin $\mathrm{L}$ and surfactin contribute synergistically to the phenotypic features of Bacillus subtilis 916 and the biocontrol of rice sheath blight induced by Rhizoctonia 
solani. Appl. Microbiol. Biotechnol. 99, 1897-1910. doi: 10.1007/s00253-0146195- 4

McKee, L. S., Martínez-Abad, A., Ruthes, A. C., Vilaplana, F., and Brumer, H. (2019). Focused metabolism of $\beta$-glucans by the soil Bacteroidetes species Chitinophaga pinensis. Appl. Environ. Microbiol. 85:e2231-18. doi: 10.1128/aem. 02231- 18

Ng, A., Weerakoon, D., Lim, E., and Padhye, L. P. (2019). Fate of environmental pollutants. Water Environ. Res. 91, 1294-1325. doi: 10.1002/wer.1225

Nishito, Y., Osana, Y., Hachiya, T., Popendorf, K., Toyoda, A., Fujiyama, A., et al. (2010). Whole genome assembly of a natto production strain Bacillus subtilis natto from very short read data. BMC Genomics 11:243. doi: 10.1186/14712164-11-243

O’Brien, P. A. (2017). Biological control of plant diseases. Austr. Plant Pathol. 46, 293-304. doi: 10.1007/s13313-017-0481-4

Price, C. L., Parker, J. E., Warrilow, A. G., Kelly, D. E., and Kelly, S. L. (2015). Azole fungicides - understanding resistance mechanisms in agricultural fungal pathogens. Pest Manag. Sci. 71, 1054-1058. doi: 10.1002/ps.4029

Qiu, D., Fujita, K., Sakuma, Y., Tanaka, T., Ohashi, Y., Ohshima, H., et al. (2004). Comparative analysis of physical maps of four Bacillus subtilis (natto) genomes. Appl. Environ. Microbiol. 70, 6247-6256. doi: 10.1128/aem.70.10.6247-6256. 2004

Qiu, D., Oshima, H., Ohashi, Y., and Itaya, M. (2003). Construction of physical maps of Bacillus subtilis (natto) strains. Nucleic Acids Res.Suppl. 2003, 207-208. doi: 10.1093/nass/3.1.207

Rao, S. K., Mathrubutham, M., Karteron, A., Sorensen, K., and Cohen, J. R. (1997). A versatile microassay for elastase using succinylated elastin. Ana. Biochem. 250, 222-227. doi: 10.1006/abio.1997.2223

Rawlings, N. D., Barrett, A. J., Thomas, P. D., Huang, X., Bateman, A., and Finn, R. D. (2017). The MEROPS database of proteolytic enzymes, their substrates and inhibitors in 2017 and a comparison with peptidases in the PANTHER database. Nucleic Acids Res. 46, D624-D632. doi: 10.1093/nar/gkx1134

Sid Ahmed, A., Ezziyyani, M., Pérez Sánchez, C., and Candela, M. E. (2003). Effect of chitin on biological control activity of Bacillus spp. and Trichoderma harzianum against root rot disease in pepper (Capsicum annuum) plants. Eur. J. Plant Pathol. 109, 633-637. doi: 10.1023/A:1024734216814

Silva, V., Mol, H. G. J., Zomer, P., Tienstra, M., Ritsema, C. J., and Geissen, V. (2019). Pesticide residues in European agricultural soils - A hidden reality unfolded. Sci. Total Environ. 653, 1532-1545. doi: 10.1016/j.scitotenv.2018.1 0.441

Smiderle, F. R., Alquini, G., Tadra-Sfeir, M. Z., Iacomini, M., Wichers, H. J., and Van Griensven, L. J. L. D. (2013). Agaricus bisporus and Agaricus brasiliensis $(1 \rightarrow 6)-\beta$-D-glucans show immunostimulatory activity on human THP-1 derived macrophages. Carbohydrate Polym. 94, 91-99. doi: 10.1016/j. carbpol.2012.12.073

Srivastava, V., Malm, E., Sundqvist, G., and Bulone, V. (2013). Quantitative proteomics reveals that plasma membrane microdomains from poplar cell suspension cultures are enriched in markers of signal transduction, molecular transport, and callose biosynthesis. Mol. Cell. Proteom. 12, 3874-3885. doi: 10.1074/mcp.M113.029033

Sundheim, L. (1992). "Effect of chitinase encoding genes in biocontrol Pseudomonas Spp," in Biological Control of Plant Diseases: Progress and
Challenges for the Future, eds E. C. Tjamos, G. C. Papavizas, and R. J. Cook (Boston, MA: Springer US), 331-333. doi: 10.1007/978-1-4757-94687_45

Swain, M. R., and Ray, R. C. (2009). Biocontrol and other beneficial activities of Bacillus subtilis isolated from cowdung microflora. Microbiol. Res. 164, 121-130. doi: 10.1016/j.micres.2006.10.009

Swain, M. R., Ray, R. C., and Nautiyal, C. S. (2008). Biocontrol efficacy of Bacillus subtilis strains isolated from cow dung against postharvest yam (Dioscorea rotundata L.) pathogens. Curr. Microbiol. 57, 407-411. doi: 10.1007/s00284008-9213-x

Swiontek Brzezinska, M., Jankiewicz, U., Burkowska, A., and Walczak, M. (2014). Chitinolytic microorganisms and their possible application in environmental protection. Curr. Microbiol. 68, 71-81. doi: 10.1007/s00284-013-0440-4

Tian, M., Huitema, E., Da Cunha, L., Torto-Alalibo, T., and Kamoun, S. (2004). A Kazal-like extracellular serine protease inhibitor from Phytophthora infestans targets the tomato pathogenesis-related protease P69B. J. Biol. Chem. 279, 26370-26377. doi: 10.1074/jbc.M400941200

Veliz, E. A., Martinez-Hidalgo, P., and Hirsch, A. M. (2017). Chitinase-producing bacteria and their role in biocontrol. AIMS Microbiol. 3, 689-705. doi: 10.3934/ microbiol.2017.3.689

Wang, X. Q., Zhao, D. L., Shen, L. L., Jing, C. L., and Zhang, C. S. (2018). "Application and mechanisms of Bacillus subtilis in biological control of plant disease," in Role of Rhizospheric Microbes in Soil: Volume 1: Stress Management and Agricultural Sustainability, ed. V. S. Meena (Singapore: Springer Singapore), 225-250. doi: 10.1007/978-981-10-8402-7_9

Weng, Y., Yao, J., Sparks, S., and Wang, K. Y. (2017). Nattokinase: an oral antithrombotic agent for the prevention of cardiovascular Disease. Int. J. Mol. Sci. 18, 523. doi: 10.3390/ijms18030523

Xiao-ying, G., Chun-e, H., Tao, L., and Zhu, O. (2015). Effect of Bacillus subtilis and Pseudomonas fluorescens on growth of greenhouse tomato and rhizosphere microbial community. J. Northeast Agric. Univ. 22, 32-42. doi: 10.1016/S10068104(16)30004-6

Yandigeri, M. S., Malviya, N., Kumar Solanki, M., Shrivastava, P., and Sivakumar, G. (2015). Chitinolytic Streptomyces vinaceusdrappus S5MW2 isolated from Chilika lake, India enhances plant growth and biocontrol efficacy through chitin supplementation against Rhizoctonia solani. World J. Microbil. Biotechnol. 31, 1217-1225. doi: 10.1007/s11274-015-1870-x

Zhao, Y., Park, R.-D., and Muzzarelli, R. A. A. (2010). Chitin deacetylases: properties and applications. Mar. Drugs 8, 24-46. doi: 10.3390/md8010024

Conflict of Interest: The authors declare that the research was conducted in the absence of any commercial or financial relationships that could be construed as a potential conflict of interest.

Copyright (C) 2020 Schönbichler, Díaz-Moreno, Srivastava and McKee. This is an open-access article distributed under the terms of the Creative Commons Attribution License (CC BY). The use, distribution or reproduction in other forums is permitted, provided the original author(s) and the copyright owner(s) are credited and that the original publication in this journal is cited, in accordance with accepted academic practice. No use, distribution or reproduction is permitted which does not comply with these terms. 